\title{
Max Uhle (1856-1944). Viajes en busca de un pasado americano
}

\author{
Max Uhle (1856-1944). Travels in search of an American past
}

Peter Kaulicke ${ }^{1}$

\begin{abstract}
Resumen
A partir de una tradición de estudios de los pueblos indígenas americanos que se remonta a Alexander von Humboldt y que en el Perú cuenta con personalidades como Johann Jakob von Tschudi y Ernst Middendorf, Max Uhle aparece en el horizonte de la historia de las ciencias como un notable continuador y un perspicaz innovador. Sus investigaciones de más de cuarenta años, de 1892 a 1933, particularmente en el ámbito andino, incluyendo Ecuador, Perú, Bolívia, el noroeste de Argentina y el centro-sur de Chile, estuvieron dedicadas a la lingüística y la etnografía, a la arqueología y a los procesos históricos de los pueblos prehispánicos. El artículo ofrece una visión de conjunto de la obra de Uhle, vinculando esos trabajos con la tradición germánica a la que pertenece, llama la intención sobre su propuesta interdisciplinaria y destaca la intencionalidad política que ese investigador atribuyó al quehacer en el campo de la historia prehispánica en el espacio sudamericano.
\end{abstract}

Palabras clave: Max Uhle, lenguas indígenas andinas, arqueologia andina, historia de Sudamérica, interdisciplinaridad científica.

\begin{abstract}
Following a tradition of studies on the Native American peoples, that dates back to Alexander von Humboldt and includes personalities like Johann Jakob von Tschudi and Ernst Middendorf in Peru, Max Uhle appears as a prominent successor and insightful innovator in the history of science. His investigations of over forty years, from 1892 to 1933, particularly in the Andean area including Ecuador, Peru, Bolivia, northwest Argentina and central-south Chile, were dedicated to linguistics and ethnography, archeology and the historical processes of the pre-Hispanic peoples. This article provides an overall view of Uhle's work, and links these works with the Germanic tradition he belongs to, calls attention on his interdisciplinary proposal and highlights the political intentionality he ascribed to pre-Hispanic historical investigations in South America.
\end{abstract}

Key words: Max Uhle, Andean indigenous languages, Andean archeology, history of South America, scientific interdisciplinarity.

${ }^{1}$ Profesor de la Pontificia Universidad Católica del Perú. 
Podría resultar algo sorpresivo contar a Uhle entre los viajeros, en el sentido de la aplicación de este término a los que recorrieron América del Sur entre el siglo XVIII y el temprano XIX. Por ello se impone primero una definición de lo que caracteriza a un viajero.

Esta figura evidentemente no se relaciona con nuestra percepción de un viajero moderno, como una persona en busca de recreo en paisajes lejanos y no tan lejanos con el afán de satisfacer su sed de curiosidad y de distracción en el ámbito de un turismo que canaliza este afán apoyado por el beneficio del negocio. El acto de viajar se reduce a una estadía más o menos prolongada en una cápsula (el avión), en la que la relación espacio/tiempo se comprime (varias horas por miles de kilómetros) y se desliga del espacio familiar (varios kilómetros sobre la superficie terrestre). El viajar, por tanto, se reduce a un traslado casi inconsciente de un lugar conocido a otro por conocer, por más apartado que este sea. Este referido afán de conocimiento es limitado, ya que suele reducirse a un encuentro breve con un "otro", cuya diferencia, marcada por la distancia tanto espacial como (supuestamente) cultural, constituye una atracción poderosa pero efímera (véase Kaulicke 2003a: XVII).

Tampoco es el viajar como profesión ejercida por personas de negocios internacionales, de vendedores con ámbitos de movimiento algo más reducidos de acuerdo al radio espacial de los lugares o de sus clientes o simplemente de personas cuyo trabajo exige viajar con frecuencia para llegar a los lugares de ocupación apartados de sus hogares.

Existía otra forma de viajes y viajeros en la Europa central, entre los siglos XVIII y XIX, incluso antes y con remanentes hasta en la actualidad. Estos se insertaban en el contexto de la costumbre de que los jóvenes abandonasen sus hogares paternales con el fin de aprender un oficio (usualmente como artesanos), para trabajar como aprendices con maestros en otras ciudades. Pasando de maestro en maestro los aprendices acababan convirtiéndose en oficiales y, luego, en maestros, gracias a la experiencia acumulada. Este proceso implica un estado "nómade", una suerte de obreros caminantes, cuyo objetivo era ganar tanto experiencia como una firme identidad propia. En el idioma alemán, esta experiencia se designa con el término Erfahrung, un sustantivo que contiene el verbo fahren que significa 'andar, viajar con o sin vehículo apropiado, por tierra o por mar'. En este sentido, el viajar implica recorrer el espacio con el fin de adquirir conocimiento por este mismo acto, y pasa a ser un requisito indispensable para la formación de la persona, que se consolida en la confrontación con el "otro", que contribuye a definir el "yo" (Kaulicke 2003a: XVII-XVIII).

Este afán de conocimiento, vinculado con los viajes, que es profundizado a través de la observación propia, la experiencia acumulada, razonada y comparada, excede el ámbito personal y gana nuevas connotaciones cuando la 
experiencia es comunicada a través de publicaciones dirigidas a lectores ávidos de aventuras y de misterios.

El viaje pasa entonces a contribuir en el afán por saciar la sed de información acerca de lo desconocido, lo lejano y exótico. Para el "Nuevo Mundo" son las crónicas de los siglos XVI y XVII las que informan a los europeos de la época acerca de supuestos paisajes paradisíacos, de riquezas inimaginables, de indígenas nobles o antropófagos, con independencia de que hubiera también intentos cuasi "modernos" de compendios más confiables, como los de Cieza de León (1984 [1553]) y Bernabé Cobo (1964 [1653]) para el ámbito del Perú. De forma general, no obstante, durante la Colonia el imaginario de lo fantástico se mantuvo vigente, envuelto en restricciones impuestas por dogmas religiosos y conceptuales, y solo se disipa en el tardío siglo XVIII.

Un nuevo concepto de viajeros y viajes relacionados con la sed de conocimientos se impone básicamente con Alexander von Humboldt (1769-1859). Su gran periplo americano, publicado en Viaje a las regiones equinoccionales del Nuevo Continente (Humboldt 1808-1825), le llevó a lo que hoy es Venezuela, Colombia, Ecuador, Perú, México, Cuba y Estados Unidos de América entre 1799 y 1804 . Humboldt era un cosmopolita cimentado en la tradición del siglo XVIII; su afán era crear una conciencia para relaciones globales (Weltbewusstsein), relaciones basadas en una comprensión intercultural y transdisciplinaria de las ciencias. Es difícil captar hoy la esencia de lo que motivaba a Humboldt y cómo se insertaba lo "humano" en su concepción de ciencia, teniendo como punto de partida la moderna separación de la ciencia en ciencias naturales y humanas o sociales.

Con su propuesta, él se convierte en iniciador de la

geografía moderna y de los estudios americanos (sobre todo de la América precolombina), uno de los investigadores más destacados de la climatología y de la geología, de la antropología y de la botánica, de la fitogeografía, estadística y cartografía; también se ha comprendido su importancia como precursor de una nueva pintura paisajística y de una mentalidad ecológica, como abogado de los derechos humanos y de la idea de la tolerancia [...]; asimismo se ha entendido su modernidad y su actualidad en calidad de filósofo y escritor (Ette 1999: 4).

Para todo ello, los viajes eran seminales; a Humboldt le sirvieron como "banco de datos" en la realización de un proyecto que le ocupará durante toda su vida. Para él era esencial contar con mapas precisos basados en mediciones exactas, controlando de este modo el espacio físico. Requería de mediciones de temperatura, de altura, de movimientos de cuerpos astronómicos, así como de la recolección y el análisis de muestras tanto de minerales y plantas como de antigüedades. Las mediciones y los análisis de las mismas se extienden a 
las estadísticas históricas, a las mediciones de las ruinas y, en este sentido, se convierten también en viajes en el tiempo. Lo que nos podría parecer como una "manía comparativa" es un medio retórico-literario para relacionar lo que aparenta ser incomparable.

Es la búsqueda de leyes globales dentro de una conciencia global, la visión del cosmos - que da título a la obra más importante de Humboldt (1845-1862) la cual lo motiva para establecer comparaciones constantes que, en su totalidad, ilustran este orden superior tanto en la naturaleza como en el ámbito social. En estas interconexiones de lo conocido y de lo desconocido, del "yo" y del "otro", experimentadas en los viajes, los caminos se convierten en arterias de una especie de organismo, cuyos elementos constituyentes requieren de un estudio pormenorizado para poder decidir su lugar y su función dentro del mismo. Tanto como los ríos y las plantas en sus ciclos de crecimiento, los caminos no siguen direcciones "lineales" sino forman un red entrelazada. En este sentido Humboldt también "viaja" entre las disciplinas que en su tiempo aún no existían como tales (véase Ette 2002a, b; Kaulicke 2003a, 2012).

Quisiera detenerme brevemente en lo que constituye la relevancia que Humboldt concede a la antigüedad americana y sus restos materiales. En su trabajo de 1806 (Humboldt 1806) postula la necesidad de un enfoque científico del estudio de los antiguos pueblos de América que se expresa en la documentación precisa de los monumentos, lo que conduce a su evaluación histórica o, más precisamente, cronológica. Piensa que la dicotomía Viejo Mundo vs. Nuevo Mundo no tiene sustento en argumentos de supuestas diferencias de edad entre ambos. Tanto en la naturaleza como en los fenómenos culturales existe una diversidad global que plantea paralelos sin necesaria vinculación directa en el campo del desarrollo cultural. Con el estudio de los monumentos, de los códices y las Denkschnüre (literalmente 'cuerdas de memoria' refiriéndose a los quipus), concluye que la historia americana debería retroceder al quinto o sexto siglo d.C., pero postula que la migración inicial es anterior, muy antigua, basándose en el desconocimiento del trigo en el Nuevo Mundo. Y en su obra Vues des Cordillères et Monumens des Peuples Indigènes de l'Amérique (Humboldt 1810), el autor reúne vistas de sitios naturales y de material arqueológico, e interconecta paisajes, clima, formación del suelo, fisionomía de las plantas o características del medioambiente con las evidencias culturales prehispánicas (véase Kaulicke 2012:1022-1025).

El impacto de Humboldt en posteriores estudiosos (viajeros) se pone en evidencia precisamente en la constatación de la vigencia duradera de su pensamiento, de modo que el arqueólogo moderno continuará siendo un viajero que se enfrenta con la naturaleza y los hombres como integrantes de ella, y también en que es transdisciplinario y comparativo "por naturaleza" (ibidem: 1028). 
Antes de abordar específicamente los aportes de Uhle a la investigación sobre los pueblos y las lenguas indígenas del Perú, es importante mencionar brevemente al suizo Johann Jakob von Tschudi (1818-1889). Debido a una circunstancia fortuita, este permaneció por cuatro años en estas tierras, tiempo que usó para viajar, estudiar y escribir un libro con el título Perú. Reiseskizzen aus den Jahren 1838-1842 (San Gall (Suiza), 1846; traducido al español en 2003 con el título El Perú. Esbozos de viajes entre 1838 y 1842). Para Tschudi el tema de viajes, que ya aparece en el título, es central como movimiento entre Europa y América, por mar y por tierra. Describe los caminos en torno de Lima y desde Lima hacia lugares de la costa y de la sierra, que vinculan la capital con el interior, llegando hasta los extremos de la selva. Describe los diferentes medios de transporte, los motivos que llevan a emprender viajes a través de una especie de red arterial que conecta los lugares con su corazón, que es Lima. La lejanía de la capital implica que la naturaleza se impone cada vez más sobre la "civilización"; además, se acerca más a poblaciones, muy esporádicas, de hombres que aún viven en un espacio casi primigenio.

Pese a las diferencias que existen entre Tschudi y Humboldt, el investigador suizo trata de emular al científico prusiano; las metas que Tschudi se autoimpone, y que cumple en gran medida, coinciden con las de Humboldt, solo que se aplica a un "microcosmos" (el Perú) en vez del cosmos (Kaulicke 2003a: XXII, XXVIII-XXXVI). Si bien Tschudi se había formado en el campo de las ciencias naturales, en particular, la zoología, sobre lo que escribe un importante trabajo (Tschudi 1844-1846), se ocupa también de otros campos del saber, en particular la filología (Tschudi 1850, 1853, 1875, 1884, 1885) y el estudio de las antigüedades (Tschudi 1844, 1878, 1891; Rivero y Tschudi 1851; para un repertorio completo de las referencias, véase Kaulicke 2001a). No queda claro dónde Tschudi adquirió sus conocimientos filológicos, pero evidentemente era buen conocedor de las fuentes relativas a la colonia (Ramírez 2001). En su introducción a Organismus der Khetsua-Sprache (1884:1-125) también se ocupa de problemas generales del origen del hombre en las Américas a partir del análisis de la lengua, la raza y la religión, y evalúa los datos referentes a los incas y la historia postincaica. Sus reflexiones, que no cabe detallar en este contexto, contienen muchos aportes relevantes (Kaulicke 2001b: 78-81). En particular llaman la atención las reservas que Tschudi tiene con respecto a las fuentes coloniales, una actitud que más tarde Uhle también hará suya. Los aportes de Tschudi al estudio de las evidencias materiales se plasman en varias obras, pero en particular en Antigüedades Peruanas, de $1851 .^{2}$

La importancia que Tschudi atribuye al estudio de los restos arqueológicos, la lengua y la historia de los indios se debe mayormente a su percepción de que

${ }^{2}$ Para las lamentables pérdidas de sus contribuciones, derivados de los malentendidos acerca de su autoría en esa obra, v. Kaulicke 2003b. 
el "indígena" estaba condenado a una pronta extinción, por lo que sus viajes y estudios se convertían en una tarea destinada a salvar el idioma y los valores culturales antes de su desaparición definitiva (Kaulicke 2003b:82).

Sus intereses fueron compartidos en gran medida por el alemán Ernst Middendorf (1830-1908), que trabajó como médico en Lima y ocasionalmente llevó a cabo negocios entre Alemania y el Perú. A diferencia de Tschudi, Middendorf permaneció más tiempo en el Perú, en total, más de 30 años. Fue solo a partir de 1885 que comenzó a emprender sus viajes; en Lima escribió sus obras durante el verano y viajó, sobre todo, durante los meses del invierno austral (para los viajes de Middendorf véase Bischof 1999:415-417). Bischof (1999:425) enfatiza que sería equivocado tildar a Middendorf de "viajero", ya que en sus 25 años de trabajo profesional en el Perú solo viajó, en total, menos de un año y medio, básicamente durante los los últimos años de su estadía en el país. Como en el caso de Tschudi, sus estudios filológicos y los de otras disciplinas parecen haberse realizado en Lima, basados en trabajos en archivos y en lectura de fuentes con algunos aportes adicionales de informantes de Acomayo y Cusco (quechua), La Paz (aimara) y Eten (muchik) (ibidem:425). Sus contribuciones a la arqueología son notables, si bien algo dispersas. En sus investigaciones detectó la existencia de por lo menos dos períodos culturales preincaicos en el Perú central, fue el primero en diferenciar Chavín de Huántar y su arquitectura monumental como fenómeno particular, así como las relaciones ente Chavín y sitios de la costa norte (Moxeke) y relaciones estilísticas entre la estela Raimondi (de Chavín de Huántar), la cerámica de la costa y la Puerta del Sol de Tihuanaco (ibidem:424, con referencias bibliográficas). Su publicación más importante son los seis volúmenes del monumental tratado Die einheimischen Sprachen Perus [Las lenguas aborígenes del Perú], de 1890-1892, con cuatro tomos sobre el quechua, uno sobre el aimara y uno sobre el muchik o mochica (1892), lo que le ha valido el epíteto "fundador de la lingüística andina" (Cerrón-Palomino 2000:274). El sexto volumen lleva el título Das Muchik oder die Chimú-Sprache. Mit einer Einleitung über die Culturvölker, die gleichzeitig mit den Inkas und Aimaràs in Südamerika lebten, und einem Anhang über die Chibcha-Sprache [El Muchik o la lengua de los chimús. Con una introducción sobre los pueblos culturales que vivían en el tiempo de los incas y los aimaras en América del Sur. Con un anexo sobre la lengua de los chibchas]. Otro importante compendio, en tres volúmenes, es Peru-Beobachtungen und Studien über das Land und seine Bewohner während eines 25jährigen Aufenthalts publicado entre 1893-1895 (vertido al español con el título Perú. Observaciones y estudios del país y sus habitantes durante una permanencia de 25 años, Lima, 1973-1974). 


\section{Uhle como viajero}

Con los antecedentes de Tschudi y Middendorf resulta poco plausible que se deba asignar un papel totalmente distinto a Uhle, sobre todo tratándose de científicos de la misma lengua y ámbito cultural y teniendo en cuenta la poca distancia temporal que los separa. Las publicaciones de Tschudi cubren un espacio entre 1844 y 1891, vale decir, en el tiempo están conectadas con las de Humboldt; las de Middendorf se concentran entre 1890 y 1895; las de Uhle referentes a América, por su parte, se inician en 1889 (véase abajo). Con ello se percibe aún una contemporaneidad y, por tanto, una continuidad, y no rupturas infranqueables o diferencias relevantes en la calidad de sus aportes.

Antes de enfocar los movimientos de Uhle en América del Sur conviene que nos detengamos brevemente en su formación. En primer lugar Uhle recibió una sólida formación académica en filología oriental bajo Georg von der Gabelentz (1840-1893), doctorándose con una tesis sobre la gramática del chino preclásico (Uhle 1880; véase Beyer 2003). En su vita Uhle enfatiza el deseo de continuar trabajando en el campo de la filología, en particular en el de las lenguas orientales, y consigue un puesto como orientalista en el Museo Etnográfico Real de Dresden en 1881 (Bankmann 1999: 1). La mayor parte de sus primeras publicaciones versa también sobre esta temática (Rowe 1954: 2628, 1998b: 338-341). En ese período inicial Uhle emprende frecuentes viajes a diferentes países de Europa con el fin de encontrar un empleo más estable. En este sentido la especulación de Rowe (1954: 1), de que el tema de su tesis le fuera impuesto carece de sustento. Definitivamente, fue por opción que Uhle no estudió prehistoria, antropología o arqueología, pese a que haya adquirido fama duradera como arqueólogo en los países sudamericanos en los que trabajó. Es más, esta última orientación le fue impuesta contra su voluntad por las circunstancias en su país y por las personas que le consiguieron un empleo en este campo, concretamente Alfons Stübel (1835-1904) y Adolf Bastian (18261905), este último discípulo de Humboldt y "Padre de la Etnología Alemana".

Stübel había emprendido, junto con Wilhelm Reiss, un viaje a América del Sur. Ese viaje los llevó a Colombia, Ecuador y el Perú, donde excavaron en Ancón. Publicaron una obra ejemplar, la primera en este ámbito basada en trabajo de campo con una documentación detallada: Das Todtenfeld von Ancón in Perú. Ein Beitrag zur Kenntnis der Kultur und Industrie des Inca-Reiches [The Necropolis of Ancon in Peru. A Contribution to our knowledge of the culture and industries of the empire of the Incas] (Berlín/Nueva York, 1880-1887, 3 tomos; véase Kaulicke 1997). Uhle realiza un registro de la colección de estos investigadores, que publica en dos tomos (Uhle 1889, 1890), y publica también un importante libro sobre Tiahuanaco, basado en la excelente documentación gráfica de Stübel (Stübel y Uhle 1892). Consigue, por lo demás, un empleo en el Museo de Etnología de Berlín, donde tiene acceso a la colección de Ancón 
y a otras que habían llegado del Perú (de Macedo [Recuay] y Centeno [Inca]), de modo que su inserción en campo de los estudios americanísticos altera su rumbo profesional original. Pero presenta también un trabajo sobre el chibcha (Uhle 1890), reconocido posteriormente por Rowe (1954: 2) como un trabajo innovador, que conservó su valor como aporte fundamental para la clasificación de la familia lingüística chibcha durante 20 años. Con base en esos trabajos tuvo una participación activa en el VII Congreso Internacional de Americanistas en Berlín en 1888, lo cual, junto con las publicaciones mencionadas, le otorgó prestigio en un campo que le era nuevo.

Finalmente, en 1892, el año de la conmemoración de los 400 años del primer viaje de Colón, Uhle llega a América, concretamente a Buenos Aires, con tres tareas principales:

1. Procurar objetos arqueológicos para la colección del Museo Etnológico de Berlín, 2. Realizar estudios etnográficos, especialmente en la observación de costumbres y usos tradicionales, así como el empleo de objetos tradicionales y 3. Reconstruir la trayectoria de la conquista de los incas desde Argentina hasta el altiplano, centro de poderío incaico, recolectando durante esta empresa datos sobre su extensión, tipo e intensidad del dominio incaico. (Liebscher 1999:51)

A partir de esta fecha Uhle permanecerá en América del Sur, con pocas interrupciones, por más de 40 años, hasta regresar a Alemania en 1933, a la edad de 77 años (para la formación de Uhle entre 1880 y 1992 véase Bankmann 1999:26, Kaulicke 2010:1-12).

Uhle no escribió un relato de viaje, como lo hicieron Humboldt, Tschudi y Middendorf, pero seguramente pasó mucho más tiempo viajando que los otros tres personajes juntos. Estos movimientos se pueden reconstruir con base en sus 175 libretas de campo (Notizbücher) inéditas, que se guardan en el Legado Uhle del Instituto Iberoamericano de Berlín. Se trata, en su mayor parte, de notas breves y y de contenido muy diverso, que no se han analizadas en su totalidad.

Para el estudio de Uhle, he propuesto cinco fases de su estadía en América del Sur (Kaulicke 2010:11-20), lo que se resume de la siguiente manera en lo que se refiere a sus viajes:

1. 1884-1896: preparación en Alemania; recorridos en Argentina y Bolivia.

2. 1886-1905: excavaciones en Pachacamac, Moche y prospecciones y sondeos en la costa y la sierra norte, la costa central y la costa y la sierra sur del Perú.

3. 1906-1911: prospecciones y excavaciones en la costa central, la sierra sur, el altiplano sur, Tiahuanaco, Cuzco, la costa y la sierra central del Perú.

4. 1912-1919: excavaciones y prospecciones en la zona de Atacama, Arica, Tacna, la zona central, Concepción (Chile) (Dauelsberg 1995). 
5. 1919-1933: Trabajos y viajes en las provincias Loja, Azuay y Cañar (Ecuador) (Höflein 2001).

Este resumen muy escueto de sus movimientos pone de manifiesto la enorme amplitud de sus recorridos, que lo llevaron a cruzar todo el continente entre Argentina y Chile y desde el norte del Ecuador hasta la parte surcentral de Chile, cubriendo buena parte de la sierra del Ecuador, prácticamente toda la costa del Perú con zonas más limitadas en la sierra, buena parte de la costa norte y norcentral de Chile hasta Concepción y la sierra de Atacama, casi toda Bolivia con excepción de la selva y buena parte del Noroeste de Argentina. Lamentablemente no existen mapas detallados de estos recorridos registrados por el propio Uhle; el de Liebscher (1999, Fig.4) es una simplificación, como demuestra la revisión de su itinerario más detalladamente (ibidem: 58-71). Boza (2004) lleva a cabo, un estudio pormenorizado de los sitios visitados y trabajados por Uhle en Bolivia, especifica los trabajos ejecutados y ofrece un índice de topónimos (ibidem: 243-307, 319-487, gráficos 15-17). Briceño (2010) presenta un detallado informe sobre el viaje de Uhle a Marca Huamachuco (sierra norte del Perú) con mapas de sus recorridos (ibidem, Figs. 1, 2, 4, 23, 26). Estas investigaciones dejan clara la utilidad de trabajar con el material inédito de Uhle, con el objetivo de reconstruir sus viajes e investigaciones de un modo bastante preciso. En esta tarea, sin embargo, hay aún un largo camino por recorrer.

\section{Uhle como filólogo y etnógrafo}

Una revisión somera del trabajo de Boza (2004: 243-307) demuestra que Uhle se dedicó a varias tareas fuera de sus estudios de los vestigios prehispánicos durante su estadía y sus viajes en Bolivia. El estudio de las lenguas quechua, aimara y uro (chipaya) por medio de registros de topónimos y por informaciones de hablantes de estas lenguas llevaron a una serie de manuscritos inéditos (ibidem: 311, véase también Wolff 2010: 383 Uro-Grammatik I y II). Uno de ellos (Vorbereitetes Uro-Vocabular) con cuatrocientas entradas léxicas del chipaya fue publicado recientemente por Cerrón-Palomino (2010), quien destaca la precisión y el valor excepcional de este documento. En el campo de la etnografía, la variedad de los temas tratados es notable. Se interesa por fiestas y bailes (véase Wolff 2010: 383, manuscrito "Los bailes de los aimara" [1907], de 66 páginas), trajes, mercados, agricultura y herramientas tradicionales, leyendas y costumbres, preparación de tradicionales recetas médicas, así como uso de los quipus modernos. Todo ello está documentado por numerosas fotos tomadas durante sus viajes, en particular de las fiestas, además de sus mediciones, excavaciones limitadas y elaboración de planos. En el Legado Uhle del Instituto Iberoamericano de Berlín se guardan casi 5.000 fotos, más de 1.000 negativos y 
3.700 placas de vidrio de los registros fotográficos hechos por Uhle, un material que en su mayor parte permanece inédito (Wolff 2010: 379-380). Una gran parte ilustra material arqueológico, no obstante, hay también motivos etnográficos en abundancia, lo que constituye otra fuente apenas explotada hasta hoy.

El ejemplo de Bolivia difícilmente puede tomarse como excepción en sus ocupaciones de viajero en comparación con los otros países donde trabajó, pero lamentablemente no hay estudios lingüísticos sistemáticos y completos acerca del material inédito de Uhle, que permitan un seguimiento sustentado y una evaluación general de sus aportes en este campo como tampoco de sus datos etnográficos sobre ese país. El propio Uhle enfatiza la relevancia de este tipo de estudios en su ponencia inaugural de director del museo de Historia Nacional de Lima en 1906:

Despertemos el pasado, reconstruyamos la grandeza de sus monumentos, de sus templos, penetremos en su espíritu estudiándolo y dando vida a las costumbres y usos, en las técnicas, en los idiomas, en el folklore y en la música de los indios de nuestros tiempos...todo lo que todavía podemos oír, ver y observar en el Perú, donde una gran parte de las costumbres antiguas aún son practicadas (Uhle 1906:413).

En el concepto de Uhle subsiste, por tanto, una continuidad entre un pasado y el presente "autóctono" o "tradicional", que sirve para poder entender el pasado. Con ello se muestra cercano a Tschudi, quien simpatiza con la cultura de los "indios" y se preocupa por su conservación mediante de la observación y la documentación. Como Tschudi y Middendorf (Middendorf 1959: 103), considera que esa tarea es una especie de rescate, justificado en muchos casos, como en el de la extinción del muchik unas décadas después de que Middendorf publicara su obra, cuya relevancia fundamental se reconoce en la actualidad. Algo parecido ocurrió con el chipaya que fue recuperado casi milagrosamente (Cerrón-Palomino 2006, Cerrón-Palomino y Ballón 2011).

\section{Uhle como historiador y arqueólogo}

Paralelamente a la relevancia innegable de sus aportes para la lingüística y la etnografía, mérito que comparte con Middendorf y Tschudi, es evidente que su contribución es fundamental en un procedimiento de trabajo que comprende la historia como arqueología y la arqueología como historia. Si bien los mencionados antecesores de Uhle ya habían intuído o incluso postularon un pasado preincaico, no dispusieron de los medios para abordarlo con base en fuentes independientes de las coloniales, las cuales son criticadas por los tres debido a sus limitaciones y por sus interpretaciones cargadas de parcialidad.

Tschudi y Middendorf vieron en los restos prehispánicos testimonios objetivos que deberían ser visitados, estudiados y documentados. Uhle se 
diferencia de ellos por un principio que Rowe (1998a:18) califica de "idea del tiempo", con lo que se refiere a diferenciaciones sustentadas por medio de la lógica de la cronología relativa, un método fundamental de la arqueología. Para ello, Uhle partió del presupuesto de que este estudio requería de trabajo de terreno, en particular la documentación y la excavación, y llega a una definición diferente del significado del proceso de colección vigente en su tiempo e incluso también en la actualidad. Fischer cita lo que Uhle escribió en 1893 a este respecto: "Las colecciones deben basarse en excavaciones, sea excavaciones de tumbas singulares o cementerios prehispánicos. Para estas excavaciones se necesita 1. dinero, 2. tiempo y 3. experiencia" (Fischer 2010: 56), con lo que se contrapone a las ideas prevalecientes entre sus auspiciadores en Alemania. Uhle poseía la experiencia a que alude, como queda en evidencia al leer sus trabajos; el dinero siempre le fue esquivo y, por períodos, el tiempo también.

Ante todo debe destacarse la gran precisión de los planos ejecutados por Uhle (véase Wurster [ed.] 1999), ejecutados con medios simples y con auxilio de la fotografía. En este sentido sigue un principio de Humboldt, referente a la "manía" por las mediciones y mediante una documentación gráfica fiel al original. Pero también se convirtió en precursor de prácticas básicas para la arqueología moderna. La documentación, junto con la excavación de superposiciones arquitectónicas y el hecho de atribuir relevancia a los contextos le han hecho merecedor del epípeto de "Padre de la Arqueología" en los países donde trabajó.

Sin embargo, Uhle va más allá de estos principios de la práctica arqueológica, lo que se plasma más nitidamente en un trabajo que constituye una propuesta de un jus historiae antiquae americanae, una "ley uniforme de la historia antigua en los países americanos", vale decir, de la historia prehispánica (Uhle 1998 [1917]). Vale la pena seguir su argumentación. Inicia la fundamentación de su propuesta de esa ley llamando la atención sobre la relevancia fundamental de la historia en la "civilización moderna", ya que esta es considerada la raíz de su existencia "i las facultades innatas que determinan su fin" (ibidem: 301). Esta historia es "como una filosofía que debe hacer comprender las fuentes de que el estado ha nacido i cuya multiplicación i desarrollo lójico tiene que dar como un resultado forzoso todo su desenvolvimiento hasta su fin" (ibidem). Uhle se percata del hecho de que los estados americanos modernos no siguen estas pautas con lo que ponen en peligro su propia pervivencia en el futuro. En su opinión, es imprescindible crear raíces profundas que se centren en la historia antigua, sin fuentes escritas. Estas raíces se han ido formado gracias a "sabios, historiadores, filólogos, antropólogos [...], extendiendo poco a poco sus respectivos estudios a las cunas de las civilizaciones europeas en los países del oriente" (ibidem: 302).

La historia de la ocupación anterior del suelo, ocupado ahora por estados modernos de América, se ha de preparar por medio de la 
arqueolojía con sus ciencias hermanas la antropología [en el sentido de la antropología física], i, en sentido menor, por la pérdida de la mayor parte de las lenguas antiguas, la lingüística (ibidem: 303 ).

Para Uhle la arqueología es una ciencia moderna y excede el "estudio i la recolección de todos los restos dejados por los antiguos habitantes antiguos [...]" con el fin de llevarlos a los museos europeos.

[Estos restos deben ser usados] para la reconstrucción del desarrollo de las civilizaciones pasadas una de otra, de los factores que han contribuido a formarlas, de sus migraciones, paulatina estensión, de las causas que sirvieron para producirlas i después a perderlas, entonces para la reconstrucción de su historia [...]. No cabe duda de que esto es posible hacer con los restos americanos antiguos, por más primitivo o desarrollado que sea el tipo a que pertenecen a veces. [...] Mirada la arqueolojía como una ciencia eminentemente histórica, ocupa un puesto de suma importancia al lado de los estudios históricos que se ocupan con los tiempos más claros modernos" (ibidem:304).

Junto con la antropología física "tienen que reconstruir unidas la completa historia del hombre precolombino" (ibidem). Uhle enfatiza la importancia fundamental o "vital" del estudio de esta historia para la legitimación de los estados modernos, ya que los cuatrocientos años después de la llegada de los europeos no bastan para "mantener su independencia, desarrollo ordenado i para el aseguramiento de los principio garantizadores de una larga existencia" (ibidem: 305). Esto se presenta como un trabajo por hacer y, evidentemente, Uhle preparó el camino y se esforzó por señalar las medidas que debían ser tomadas. Pero llamó la atención de que no sólo falta el interés por esta historia, sino también sobre el hecho de que se está destruyendo de manera alarmante lo que queda de ese pasado, como se manifiesta en múltiples ejemplos (ibidem:305-312), y en seguida advierte

[a los estados americanos ahora] la historia les parece de poca importancia, gozan su vida como no hubiese de venir el tiempo en que necesitarán las fuerzas sacadas de las enseñanzas del pasado para mantenerse derechos. Sin embargo este tiempo ha de venir como ha venido a los otros estados modernos del mundo. Vendrá por eso el tiempo en que por necesidad se habrán de acordar de las fuentes de la historia precolombina [...]. Entonces les faltarán las raíces profundas echadas en el suelo por medio de la historia, i como plantas acuáticas sin raíces parecerán espuestos a ser desalojados por el viento en el océano del continente que nunca habían hecho suyo penetrando en su pasado (ibidem: 312 ).

Uhle utiliza estos argumentos con el propósito de proponer medidas precisas para la documentación, la conservación y el estudio de estos restos históricos 
precolombinos, abogando por una colaboración estrecha entre los estados americanos (los Estados Unidos de América incluidos), por medio de una ley aceptada por todos. Nos interesa esta globalización o internacionalización de historias compartidas, que requiere de otra justificación, que Uhle también proporciona.

Por su configuración geográfica especial el continente forma, más que otras grandes partes de nuestro planeta, una unidad también con respecto al orijen de su población antigua i al desarrollo de sus civilizaciones. Más que en otras partes del mundo se imponen por eso problemas sobre el orijen de sus poblaciones primitivas[,] condensados en cuestiones precisas sobre las cunas de la primera inmigración i la afinidad de sus razas con otras. [...] Los tipos de la antigua población presentan una enorme variedad en el norte i sur, i casi en todas partes simultáneamente, cuya descendencia u orijen común sólo se puede aclarar con el concurso científico de todos los países. [...] Las poblaciones antiguas de América forman también en su hábito esterior algunas grandes familias que se han limitado, sobrepuesta una a otra, entrelazado de diferente manera no explicable sino por el estudio aferrado por científicos de todos los países. [...] También la unidad del desarrollo es más grande en América que en cualquier otro continente de iguales dimensiones. Hai vestijios de una capa original de civilización primitiva con numerosos objetos de carácter paleolítico en las rejiones más distantes del continente (ibidem:325).

Uhle propone una difusión de "civilización superior" de la parte central hacia "los Estados Unidos, Colombia, las Antillas i el Perú, como otros centros secundarios de su dilatación a Venezuela, la costa de Brasil i todo el este del continente del Perú a Ecuador, Bolivia, la Argentina i gran parte de Chile" (ibidem), pero falta estudiar el carácter del desarrollo del centro y de los mecanismos involucrados en su dispersión.

Las antiguas civilizaciones de Colombia se estendieron por toda la costa i casi por toda la sierra del Ecuador, sin que supiésemos en que periodo principió a estenderse a estas rejiones. Ciertos caracteres de la civilización colombiana i centroamericana se introdujeron temprano por la sierra del Ecuador i muchos grados de latitud hasta el interior del Perú, pero nos falta el entendimiento del momento i de la forma exacta en que este proceso se consumó. [...] La época de las primeras relaciones civilizadas del Perú con el interior de la Arjentina forma también un problema no resuelto aún. Cual era la relación de los primeros habitantes de la altiplanicie de Bolivia como los Uros con los primeros habitantes del este, como se explican numerosas relaciones lingüísticas de los araucanos con tribus del sudeste de Brasil, son, como innumerables otras, cuestiones, que, para entender 
mejor el desarrollo de la comunicación ente los antiguos habitantes del continente, esperan su solución de los estudios en el porvenir (ibidem: 325-326).

Con independencia de este llamado a la cooperación internacional, Uhle es consciente de los problemas.

La soberanía de cada uno de los estados en su territorio, respecto al cultivo de sus intereses materiales e intelectuales, es de absoluta intanjibilidad. ¿Pero es esta una razón que justifique la resolución de hacerse perder tanto los intereses de historia individual como de la historia del continente mancomunmente ocupado, pareciendo que la soberanía individual se opone a la colaboración en una obra que interesa a todos? (ibidem: 327).

Se ha citado este texto en forma exhaustiva porque muestra perspectivas sobre Uhle que señalan, por una parte, diferencias con Humboldt, Tschudi y Middendorf y, por otro, avances en la definición de problemas fundamentales. Más que los otros autores referidos, Uhle contó con una consistente preparación para su prolongada estadía en cinco países sudamericanos, gracias a su formación de filólogo, etnógrafo y, en menor grado, de arqueólogo. Más que Tschudi y Middendorf, Uhle contaba también con una experiencia personal minuciosa a través de centenares de sitios que recorrió en el curso de sus numerosos viajes.

En este sentido la experiencia de Uhle responde al sentido referido en la introducción de este trabajo: adquirir conocimiento a través de los viajes.

Tiene en común con Humboldt una visión global de interrelaciones complejas, y también se opone a las tendencias nacionalistas que en el tiempo de Humboldt aún no se habían manifestado de manera tan pronunciada. Y, en general, Uhle comparte con los otros tres investigadores mencionados aquí, sus intereses inter- o transdisciplinarios, una concepción de la historia que incorpora diversas disciplinas, así como lo que se refiere a la relación del hombre con el medioambiente y la relevancia de los movimientos en el espacio, cuya direccionalidad se define a partir de un centro.

No obstante, Uhle se diferencia también decisivamente de sus antecesores en la aplicación de métodos más rigurosos, la definición de la historia dentro de marcos sincrónicos y diacrónicos, partiendo de historias locales - como en su excavación en Pachacamac (Uhle 1903) y Moche (Uhle 1913) -, con vestigios que son seguidos en el tiempo, a través de la estratigrafía y por la comparabilidad que aplica a un espacio mayor, con otras historias paralelas o diferentes. Esta experiencia de historias equivale también a viajes al pasado, durante los cuales Uhle se acerca cada vez más a lo que busca: los "orígenes". Estos orígenes, si bien también podrían servir y, de hecho, sirvieron para fines políticos nacionalistas, Uhle enfatiza la noción de origen con un sentido más 
global. La propuesta de la existencia de largas historias entrelazadas de las Américas le permite insertar ese devenir histórico en la historia universal, de la misma forma que, en otros análisis, la historia de Europa pudo ser vinculada con otras historias en Asia. Esta idea, desde luego, no es totalmente distinta de la de Humboldt, pero Uhle quiere procurar medios más sólidos para definirla y para consolidar las comparaciones con datos sustentados en una colaboración científica internacional.

Si bien esta visión de Uhle abrió paso a avances, prevalecen aún los problemas que él previó con casi un siglo de anterioridad. Autoidentificaciones nacionales siguen buscándose sin que los logros del conocimiento arqueológico hayan llegado a convertirse en las sólidas historias que él postulaba. Existen comunicaciones internacionales, pero corren paralelas con nacionalismos, que ganan fuerza como respuesta a un globalismo agresivo. También existen leyes internacionales para la protección del patrimonio prehispánico, pero son ineficientes. Los sitios arqueológicos, en cambio, van convirtiéndose en lugares preferidos por los "viajeros", pero esto ocurre en el sentido que fue definido inicialmente, vale decir, en muestras palpables de un exotismo que no requiere comprensión.

\section{Referencias}

Bankmann, Ulf. 1999 Aufbruch und Rückkehr. Die Berliner Zeit im Leben Max Uhles. En: Ursula Thiemer-Sachse y Peter Masson (eds.). Estudios andinos: Max Uhle, su obra, y su repercusión, 11-36, Indiana 15. Berlín.

Beyer, Lothar. 2003. Max Uhle y su doctorado en la Universidad de Leipzig, Alemania. Investigaciones Sociales VII (1), 107-122. Lima.

Bischof, Henning. 1999. Ernst Wilhelm Middendorf: Medical Doctor-Andean Scholar. Keilhau (Thuringia), December 31, 1830 - Colombo (Ceylon/Sri Lanka), February 6, 1908, Baessler-Archiv, Neue Folge, XLVII, 397-445.

Boza, Beatriz. 2004. Itinerarios de Max Uhle en el altiplano boliviano. Sus libretas de expedición e historia cultural (1893-1896), Indiana Suplemento 15. Berlín.

Briceño, Jesús. 2010. Markahuamachuco y la sierra del departamento La Libertad, norte del Perú: la contribución de Uhle. En: Peter Kaulicke, Manuela Fischer, Peter Masson y Gregor Wolff (eds.). Max Uhle (1856-1944, Evaluaciones de sus investigaciones y obras. Lima: Fondo Editorial de la Pontificia Universidad Católica del Perú; 205-231

Cerron-Palomino, Rodolfo. 2000. Lingüística Aimara. Biblioteca de la Tradición Oral Andina 21, Centro de Estudios Regionales Andinos Bartolomé de las Casas. Cuzco. . 2006. El chipaya o la lengua de los hombres del agua. Lima: Fondo Editorial de la Pontificia Universidad Católica del Perú.

. 2010. Max Uhle: “descubridor" del chipaya. En: Peter Kaulicke, Manuela Fischer, Peter Masson y Gregor Wolff (eds.) Max Uhle (1856-1944, Evaluaciones 
de sus investigaciones y obras. Lima: Fondo Editorial de la Pontificia Universidad Católica del Perú; 79-92.

Cerrón-Palomino, Rodolfo y Enrique Ballón. 2011. Chipaya: léxico- etnotaxonomía Lima: Fondo Editorial de la Pontificia Universidad Católica del Perú.

Cieza de León, Pedro. 1984 [1553]. Crónica del Perú. Primera Parte. (Introducción Franklin Pease), Colección Clásicos Peruanos, Pontificia Universidad Católica del Perú/ Academia Nacional de Historia. Lima.

Cobo, Bernabé. 1964 [1653]. Historia del Nuevo Mundo II. En: Obras del Padre Bernabé Cobo (estudio preliminar y edición de P.F. Mateos), Biblioteca de Autores Españoles 92. Madrid.

Dauelsberg, Percy. 1995. Dr. Max Uhle: su permanencia en Chile, de 1912 a 1929. Beiträge zur Allgemeinen und Vergleichenden Archäologie 15, 371-394.

Ette, Ottmar. 1999. Humboldt y el proyecto moderno. Humboldt 126, 2-5, InterNationes. Bonn. .2002a. "dass es einem leid tut, wie er aufgehört hat, deutsch zu sein". Alexander von Humboldt, Preussen und Amerika. Humboldt im Netz III, 4.

.2002b. Weltbewusstsein. Alexander von Humboldt und das unvollendete Projekt einer anderen Moderne. Göttingen: Velbrück Wissenschaft.

Fischer, Manuela. 2010. La misión de Max Uhle para el Museo Real de Etnología en Berlín (1892-1895): entre las ciencias humboldtianas y la arqueología americana. En: Peter Kaulicke, Manuela Fischer, Peter Masson y Gregor Wolff(eds.). Max Uhle (1856-1944, Evaluaciones de sus investigaciones y obras. Lima: Fondo Editorial de la Pontificia Universidad Católica del Perú; 49-62.

Höflein, Michael. 2002. Leben und Werk Max Uhles. Eine Bibliographie, IberoBibliographien 1. Berlin: Ibero-Amerikanisches Institut Preussischer Kulturbesitz.

Humboldt, Alexander von. 1806. Über die Urvölker von Amerika und die Denkmähler welche von ihnen übrig geblieben sind. Vorgelesen in der Philomantischen Gesellschaft. Jänner 1806, Neue Berlinische Monatsschrift 15, 177-208. Berlin: Stettin.

1808-1825. Voyage aux régions equinoxiales du Nouveau Continent fait en 1799, 1800, 1801, 1802, 1803 et 1804 par Alexandre de Humboldt et Aimé Bonpland, rédigé par A. de Humboldt, 30 tomos, Grande édition, Schoell, Dufour, Maze et Gide. Paris.

. 1810 Vue des Cordillères et Monumens des Peuples Indigènes de l'Amérique. París.

1845-1862 Kosmos. Entwurf einer physischen Weltbeschreibung, 5 tomos. Stuttgart/Tübingen.

Kaulicke, Peter. 1997. Contextos Funerarios de Ancón. Esbozo de una síntesis analítica. Lima: Fondo Editorial, Pontificia Universidad Católica del Perú.

. 2001a. La vigencia de Johann Jakob von Tschudi, En: Peter Kaulicke (ed.) Aportes y vigencia de Johann Jakob von Tschudi (1818-1889), 29-62. Lima: Fondo Editorial, Pontificia Universidad Católica del Perú. 
. 2001b. Visiones del pasado de Johann Jakob von Tschudi. En: Peter Kaulicke (ed.). Aportes y vigencia de Johann Jakob von Tschudi (1818-1889). Lima: Fondo Editorial, Pontificia Universidad Católica del Perú; 75-95.

. 2003a. Introducción, en Johann Jakob von Tschudi, El Perú. Esbozos de viajes realizados entre 1838 y 1842 [trad. de Tschudi 1846]. Lima: Fondo Editorial, Pontificia Universidad Católica del Perú.

. 2003b. Visiones del pasado de Johan [sic] Jakob von Tschudi. Société suisse des Américanistes Bulletin 66-67, 77-84.

. 2010. La vida y obra de Friedrich Max Uhle. Recientes logros, problemas y perspectivas, en Peter Kaulicke, Manuela Fischer, Peter Masson y Gregor Wolff (eds.). Max Uhle (1856-1944, Evaluaciones de sus investigaciones y obras. Lima: Fondo Editorial de la Pontificia Universidad Católica del Perú; 9-24.

2012. La comprensión del pasado preeuropeo americano de Humboldt y la arqueología en el Perú, en Margarita Guerra Martinière y Rafael Sánchez-Concha Barrios (eds.) Homenaje a José Antonio del Busto Duthuburu. Lima: Fondo Editorial, Pontificia Universidad Católica del Perú; II, 1019-1030.

Liebscher, Verena. 1999. Reisen und Werk Max Uhles von 1892-1911 / Viajes y obra de Max Uhle de 1892-1911. En: Wolfgang W. Wurster (ed.). Pläne archäologischer Stätten im Andengebiet/Planos de sitios arqueológicos en el área andina. AVAMaterialien 56, 43-87, Ibero-Amerikanisches Institut Preussischer Kulturbesitz, Berlin / Kommission für Allgemeine und Vergleichende Archäologie des Deutschen Archäologischen Instituts, Bonn. Mainz.

Middendorf, Ernst. 1890-1892. Die einheimischen Sprachen Perus. Leipzig: F.A. Brockhaus; tomos 1-6.

. 1893-1895. Peru-Beobachtungen und Studien über das Land und seine Bewohner während eines 25jährigen Aufenthalts. Berlín: Robert Oppenheim (Gustav Schmidt); tomos 1-3.

. 1959. Las lenguas aborígenes del Perú (proemios e introducciones al quechua, al aimara y al mochica. Versiones de Emilio Althaus, Franz Tamayo y Federico Kauffmann). Prólogo, recopilación, revisión y traducción parcial de Estuardo Núñez. Instituto de Literatura de la Facultad de Letras Publicación 8, Universidad Nacional Mayor de San Marcos. Lima.

. 1973-1974. Perú. Observaciones y estudios del país y sus habitantes durante una permanencia de 25 años. Trad. de Middendorf 1893-1895, de Ernesto More. Universidad Nacional Mayor de San Marcos. Lima.

Ramírez, Pedro. 2001. El diccionario trilingüe de J.J. von Tschudi y sus fuentes. En: Peter Kaulicke (ed.). Aportes y vigencia de Johann Jakob von Tschudi (1818-1889). Fondo Editorial, Pontificia Universidad Católica del Perú. Lima; 101-133.

Rowe, John H. 1954. Max Uhle, 1856-1944. A memoir of the father of Peruvian archaeology. University of California Publications in American Archaeology and Ethnology 46, Berkeley y Los Angeles.

1998a. Max Uhle y la idea del tiempo en la arqueología americana, En: Peter 
Kaulicke (ed.). Max Uhle y el Perú Antiguo. Fondo Editorial, Pontificia Universidad Católica del Peru, Lima; 5-21.

1998b. Bibliografía de Max Uhle. En: Peter Kaulicke (ed.). Max Uhle y el Perú Antiguo. Fondo Editorial, Pontificia Universidad Católica del Peru, Lima; 337-363.

Reiss, Wilhelm y Alfons Stübel. 1880-1887. Das Todtenfeld von Ancon in Peru. Ein Beitrag zur Kenntnis der Kultur und Industrie des Inca-Reiches. Berlín: A. Asher; 3 tomos.

Rivero y Ustáriz, Mariano y Juan Diego de Tschudi. 1851. Antigüedades peruanas. Viena: Impresa Imperial de la Corte y del Estado.

Stübel, Alfons y Max Uhle. 1892. Die Ruinenstätte von Tiahuanaco im Hochlande des alten Peru. Eine kulturgeschichtliche Studie auf Grand selbständiger Aufnahmen. Breslau: C.T, Wiskott.

Tschudi, Johann Jakob von. 1844. Über die Ureinwohner von Peru. Müller's Archiv für Anatomie, Physiologie und wissenschaftliche Medicin 1843, 98-109.

1844-1846. Untersuchungen über die Fauna Peruana auf einer Reise in Peru während der Jahre 1838-1842. San Gall: Scheitlin und Zollikofer.

. 1846. Peru. Reiseskizzen aus den Jahren 1838-182. San Gall: Scheitlin und Zollikofer.

. 1850. Über die Sprachen Amerikas im allgemeinen und insbesonders über diejenigen des westlichen Theiles des mittleren Südamerika [Acerca de las lenguas americanas en general y paticularmente sobre las lenguas de la parte occidental de Sudamérica central]. Sitzungsberichte der Kaiserlichen Akademie der Wissenschaften in Wien, Philosophisch- Histoirische Classe 1850(1), 282-282. Viena.

. 1853. Die Ketschua-Sprache. Viena: Kaiserlich-Königliche Staatsdruckerei.

. 1875 Ollanta. Ein altperuanisches Drama aus der Ketschuasprache, übersetzt und commentiert von J.-J. von Tschudi. Viena: K. Gerold's Sohn.

. 1884. Organismus de Ketschua-Sprache. Leipzig: Brockhaus.

. 1885. Die geographischen Namen in Peru. Ein onomatologischer Beitrag. Zeitschrift für wissenschaftliche Geographie 5, 349-355. Traducción en Peter Kaulicke (ed.). 2001. Aportes y vigencia de Johann Jakob von Tschudi (1818-1889). Lima: Fondo Editorial, Pontificia Universidad Católica del Perú; 227-243.

1891. Culturhistorische und sprachliche Beiträge zur Kenntnis des alten Peru, Denkschriften der kaiserlichen Akademie der Wissenschaften in Wien, Philosophisch-Historische Classe 39, Viena. Trad. Contribuciones a la historia, civilización y lingüística del Perú antiguo, Boletín de la Sociedad Geográfica de Lima 104(1) (1985), 1-212.

2003. El Perú. Esbozos de viajes realizados entre 1838 y 1842. Edición y traducción [Tschudi 1846] de Peter Kaulicke. Lima: Fondo Editorial, Pontificia Universidad Católica del Perú.

Uhle, Max. 1880. Die Partikel wei im Schu-king und Schi-king. Ein Beitrag zur Grammatik des vorklassischen Chinesisch. Leipzig: Alexander Edelmann. 
. 1889-1890. Kultur und Industrie südamerikanischer Völker. Nach den im Besitze des Museums für Völkerkunde zu Leipzig befindlichen Sammlungen von A. Stübel und W. Reiss. Tomo 1: Alte Zeit [1889]; tomo 2: Neue Zeit [1890]. Berlín: A. Asher \& Co.

. 1890. Verwandschaften und Wanderungen der Tschibtscha. En: VII Congrès International des Américanistes, Berlin; 466-489.

. 1903. Pachacamac. Report of the William Pepper, M.D., II.D., Peruvian Expedition of 1896. Philapelphia: The Department of Archaeology of the University of Pennsylvania.

. 1906. Discurso de incorporación al Instituto Histórico del Perú. Revista Histórica 1, 408-414. Lima.

1913. Die Ruinen von Moche. Journal de la Société des Américanistes 10, 95-117. Traducción en Peter Kaulicke (ed.). 1998. Max Uhle y el Perú antiguo; 205-227.

. 1917. Conveniencia de dictar una ley uniforme en los países americanos, para proteger y estimular el estudio y la recolección de material arqueológico y antropológico: estudio presentado ante el Segundo Congreso Científico Panamericano, Washington, E.U de América, diciembre 27, 1915-eneo 8, 1916, Washington D.C. Reedición en Peter Kaulicke (ed.). 1998. Max Uhle y el Perú antiguo; 301-335.

Wolff, Gregor. 2010. El legado Max Uhle en el Instituo Ibero-Americano de Berlín. En: Peter Kaulicke, Manuela Fischer, Peter Masson y Gregor Wolff (eds.). Max Uhle (1856-1944, Evaluaciones de sus investigaciones y obras, 379-384. Lima: Fondo Editorial de la Pontificia Universidad Católica del Perú.

Wurster, Wolfgang W. (ed.). 1999. Pläne archäologischer Stätten im Andengebiet/ Planos de sitios arqueológicos en el área andina. AVA-Materialien 56, IberoAmerikanisches Institut Preussischer Kulturbesitz, Berlín / Kommission für Allgemeine und Vergleichende Archäologie des Deutschen Archäologischen Institut, Maguncia.

Data recebimento: 05/11/2014.

Data aceite: 20/11/2014. 